\title{
Using remote sensing and numerical modelling to quantify a turbidity discharge event in Lake Garda
}

\author{
Nicola Ghirardi, ${ }^{1 *}$ Marina Amadori, ${ }^{1,2}$ Gary Free, ${ }^{1}$ Lorenzo Giovannini, ${ }^{2}$ Marco Toffolon, ${ }^{2}$ Claudia Giardino, ${ }^{1}$ \\ Mariano Bresciani ${ }^{1}$ \\ ${ }^{1}$ Institute for Electromagnetic Sensing of the Environment, National Research Council (CNR-IREA), Via Bassini 15, 20133 Milan; \\ ${ }^{2}$ Department of Civil, Environmental and Mechanical Engineering (DICAM), University of Trento, Italy
}

\begin{abstract}
We investigate the effect of the Adige-Garda spillway opening on the 03/03/2020 on Lake Garda using numerical modelling and maps of Suspended Particulate Matter (SPM) concentration. SPM maps are obtained from Sentinel-2 images processed using the BOMBER bio-optical model. Three satellite images are examined: 28/02/2020, 04/03/2020 and 07/03/2020. Maps indicate a significant increase in SPM concentrations, especially in the northern part of the lake close to the hydraulic tunnel outlet. Results are consistent with the modelled flow field. Remote sensing effectively captures the event's spatial and temporal variation, while numerical modelling explains and corroborates the observed patterns.
\end{abstract}

\section{INTRODUCTION}

There are several in situ methods to evaluate the variation of turbidity and other parameters in a water body (e.g., Secchi Disk, turbidimeters or multiparameter probes). These types of observations can be used to obtain information on the trophic state of aquatic ecosystems. However, in situ measurements are limited by several factors, including economic and time cost, and the need of punctual investigation. The use of remote sensing techniques can be a cost-effective alternative to provide multitemporal and spatial information on water quality conditions at the surface layers on a large scale (Bresciani et al., 2011). Suspended Particulate Matter (SPM) concentration is one of the many physical characteristics of water bodies that can be assessed by remote sensing, and, in lakes, it is often related to the inflow of riverine waters. Indeed, river inflows carry significant sediment load in

Corresponding author: ghirardi.n@irea.cnr.it

Key words: Adige-Garda spillway; SPM concentration; water quality monitoring; Sentinel-2; WRF+Delft3D; atmosphere-lake simulation.

Edited by: Diego Fontaneto, CNR IRSA, Verbania, Italy.

Received: 3 August 2020.

Accepted: 23 September 2020.

This work is licensed under a Creative Commons Attribution NonCommercial 4.0 License (CC BY-NC 4.0).

${ }^{\circ}$ Copyright: the Author(s), 2020

Licensee PAGEPress, Italy

J. Limnol., 2021; 80(1):1981

DOI: 10.4081/jlimnol.2020.1981 lakes and affect water quality not only directly by introducing nutrients, contaminants and thermal energy, but also indirectly by altering the lake's circulation and mixing dynamics. Depending on the density difference existing between the riverine and lacustrine waters, which is influenced by the relative values of temperature, salinity and turbidity, the hydrodynamic effect of the river inflows can be either seen as: i) overflows, i.e. buoyant river plume on denser lake surface water; ii) interflows, i.e. intrusive river plume reaching the depth of equivalent lake density; iii) underflows, i.e. bottom density currents (De Cesare et al., 2006). In the latter case, the plunging river plume, when reaching the lake bottom, might lift up the nutrient-rich hypolimnetic layer, thus mobilizing phosphorus from deep to surface waters. The continuous supply of water rich in nutrients and organic matter can lead to a marked longitudinal heterogeneity in the limnological characteristics of a lake (Kimmel et al., 1990). In addition, a sudden increase in turbidity suppresses the penetration of light into the water column, which can lead to negative effects on zooplankton and fish (Jacobsen et al., 2014), and more generally on the entire aquatic ecosystem.

Here, we investigate the effect of the introduction of water from the Adige river, via the Adige-Garda spillway, on the SPM concentration of Lake Garda. Our method combines remote sensing techniques and meteorological and hydrodynamic numerical modelling tools. The synergistic use of these two approaches can ensure mutual reliability and provides useful insights on the physical processes behind the observed patterns (Soulignac et al., 2018). We quantify for the first time the increase in SPM concentration resulting from the spillway discharge, providing useful information for lake management.

Lake Garda is the largest Italian lake, located $65 \mathrm{~m}$ asl in the subalpine region. It has an area of $368 \mathrm{~km}^{2}$, a volume of $49 \mathrm{~km}^{3}$, with a maximum and mean depth of $346 \mathrm{~m}$ and 133 m, respectively (Fig. 1A). Lake Garda can be classified 
as an oligo-mesotrophic lake, where a full water circulation occurs only during cold and windy winters (Salmaso et al., 2003). The average value of Secchi disk depth significantly varies on a seasonal basis: in summer it is $4.5 \mathrm{~m}$, while in winter it reaches up to $16 \mathrm{~m}$. According to Premazzi et al. (2003), the SPM concentration spans a winter-summer range between 0.1 and $5.5 \mathrm{~g} \mathrm{~m}^{-3}$ (average value $2.5 \mathrm{~g} \mathrm{~m}^{-3}$ ), while chlorophyll-a between 0.5 and $12 \mathrm{mg} \mathrm{m}^{-3}$ (average value $2.7 \mathrm{mg} \mathrm{m}^{-3}$ ). Lake Garda is also an important tourist site and a strategic water supply for agriculture, industry, energy, fishing and drinking.

In 1959, the hydraulic tunnel of the Adige-Garda spillway was completed. It is an artificial tunnel $10 \mathrm{~km}$ long and its role is to reduce the hydrometric level of the Adige river during flood events by discharging excess riverine waters into Lake Garda. In this way, the flooding of the downstream city of Verona can be prevented. This spillway transfers up to $500 \mathrm{~m}^{3} \mathrm{~s}^{-1}$ from the Adige river to the lake, taking advantage of the natural difference in altitude between the entrance and the exit. The tunnel has been used rarely and only in situations of high flood risk. From 1960 to 2018, the Adige-Garda spillway was opened only 11 times for flood defense, with a volume of water discharged between 6 and 79 million $\mathrm{m}^{3}$ per single flood event and a peak flow between 100 and $492 \mathrm{~m}^{3} \mathrm{~s}^{-1}$.

The last opening of the tunnel for flood defense was on the 29/10/2018 due to a dangerous increase in the water level of the Adige river during a flood event. On that occasion, 17.5 million $\mathrm{m}^{3}$ of water was discharged into the lake, causing a $5 \mathrm{~cm}$ rise in lake water level and the inflow of colder water rich in debris, silt, trees and rubbish collected along the banks of the river. During past opening events, serious concerns were raised about the woody and plant debris delivered to the lake and most importantly about the effects of the flush of riverine water, which is significantly different from lacustrine waters in terms of temperature and nutrient concentration. Indeed, the local microclimatic alteration due to the cold water intrusion and the introduction of nutrients (and possibly pollutants, e.g. heavy metals from industrial effluents) might cause fish deaths and blooms of alien algal species. Although these concerns prevented a more frequent use of the tunnel, at present, and to our knowledge, no studies have shown the effects of the discharge of Adige river's water on Lake Garda. In addition to its use during extreme events, the spillway is opened routinely for leakage tests, cleaning and maintenance. In this work, we analyse the routine opening of the $03 / 03 / 2020$, when a total water volume of $473^{\prime} 000 \mathrm{~m}^{3}$ was discharged in the afternoon, from 13:00 to 20:00 UTC.

\section{METHODS}

Sentinel-2 (S2) images were used to assess SPM concentrations in the lake before and after the opening event of the $03 / 03 / 2020$. In particular, the following three overpasses were available: 28/02/2020, 04/03/2020 and 07/03/2020. S2 images were downloaded from the Copernicus Open Access Hub. The twin satellites of Sentinel-2 (S2A and S2B) carry on board the MultiSpectral Instrument (MSI) optical sensor, which acquires images in 13 bands (from 442 to $2201 \mathrm{~nm}$ ), with a spatial resolution of 10,20 , and $60 \mathrm{~m}$ (depending on the spectral band), at a frequency of 5 days. For this study, the first 7 bands of the VIS-NIR region were used, all reprocessed at the spatial resolution of $10 \mathrm{~m}$. Using the SNAP tool "ReflectanceToRadianceOp", the Top of Atmosphere (TOA) radiances were obtained. TOA radiance products were then atmospherically corrected with the Second Simulation of the Satellite Signal in the Solar Spectrum codevector version (6Sv) (Vermote et al., 2006). The 6Sv code was parametrized with aerosol values $\left(\mathrm{AOD}_{550}\right)$ referring to the acquisition dates and obtained through a NASA application (https://giovanni.gsfc.nasa.gov/giovanni/). The $6 \mathrm{~Sv}$-derived reflectance was converted into remote sensing reflectance (Rrs) dividing by $\pi$. The Rrs products were then used as input for the bio-optical model BOMBER (Giardino et al., 2012), to estimate the SPM concentrations. The model was applied in "deep water" mode and for each image was run on the mask of the northernmost part of the lake, excluding the coastal areas, in order to avoid bottom disturbance (Fig. 1A). The parametrization used in BOMBER has been already utilised in previous work (Giardino et al., 2014). Once the SPM maps were created, five regions of interest (ROI), each with an area of $50 \times 50 \mathrm{~m}^{2}$, were chosen to track the spreading of the SPM in the available dates (Fig. 1A). The 5 ROIs (R1R5) were selected within the study area along a transect from the outlet of the tunnel towards the southern deeper waters.

The thermo-hydrodynamics of Lake Garda were simulated with the hydrodynamic model Delft3D (Lesser $e t$ al., 2004) fed by the results of the Weather Research and Forecasting (WRF) atmospheric model (Skamarock et al., 2008). The modelling chain adopted in this study was tested for the first time on Lake Garda by Amadori et al., (2018), and subsequently used to investigate basin scale circulation by Amadori et al., (2020). The numerical simulation was run from 26/02/2020 until 08/03/2020. The atmospheric model was run with hourly data assimilation from 11 stations and provided high resolution space (500 $\mathrm{m})$ and time (15 $\mathrm{min})$ varying meteorological forcing, i.e. air temperature and pressure, wind, relative humidity, incoming solar radiation and cloud cover. Cloud cover was obtained as the sum of the values (with upper limit 1, i.e. completely overcast sky) calculated by the meteorological model in the vertical levels between $925 \mathrm{hPa}(\sim 750 \mathrm{~m}$ asl) and $500 \mathrm{hPa}(\sim 5500 \mathrm{~m}$ asl). Such forcing was used as boundary condition for the hydrodynamic model to 
compute heat fluxes and wind stress at the interface between air and water. The hydrodynamic model has a horizontal mesh of $100 \mathrm{~m}$ (on average) and 100 vertical layers of thickness increasing from $1 \mathrm{~m}$ (surface) to $25 \mathrm{~m}$ (bottom) and was initialized with the vertical water temperature profile (Fig. 1B) measured by the Environmental Protection Agency (APPA) of the Autonomous Province of Trento on the 26/02/2020 (CTD deployed at point P1 in Fig. 1A). Hourly water temperature data at $10 \mathrm{~m}$ depth (buoy in point P2 in Fig. 1A) were used for comparison with the model results. The Adige-Garda inflow was set up as a time varying discharge according to the flow rate provided by the Service for Torrent Control of the Province of Trento. The temperature of the inflow coincides with the Adige river water temperature sampled at an hourly rate by APPA at Canale Biffis monitoring station (point P3 in Fig. 1A). The river water temperature (P3) was always colder than the lake water temperature at $10 \mathrm{~m}$ depth (P2), both during the opening event (when the difference was $\sim 3.5^{\circ} \mathrm{C}$ ) and in the subsequent days (Fig. 1C). The inflow's suspended solids concentration was estimated as ranging between 100 and $400 \mathrm{~g} \mathrm{~m}^{-3}$, based on a power function of the water discharge (Syvit- ski et al., 2000), whose coefficients were calibrated for the specific event according to the observed variations of SPM from S2 maps. No information was available to characterize the sediment transport in the tunnel and in the lake. Hence, considering also that the focus of the analysis is on the SPM concentration at the lake surface, which is mainly due to the slowly settling fraction (wash load), SPM was modelled as a passive tracer. Thus, the intrusion depth of the riverine water resulted from the difference in water temperature only (Fig. 1C), as no SPM profiles are measured in the lake, to our knowledge. The initial condition for the SPM numerical tracer was set as vertically uniform and equal to $0.32 \mathrm{~g} \mathrm{~m}^{-3}$, according to the value detected from S2 maps on the $28 / 02$.

\section{RESULTS}

Fig. 2A shows the maps of SPM concentrations obtained from the satellite images: significant changes in SPM concentrations occurred among the three available dates. The percentage variation is quantified for the 5 ROIs (R1-R5) in Tab. 1, together with the results of the
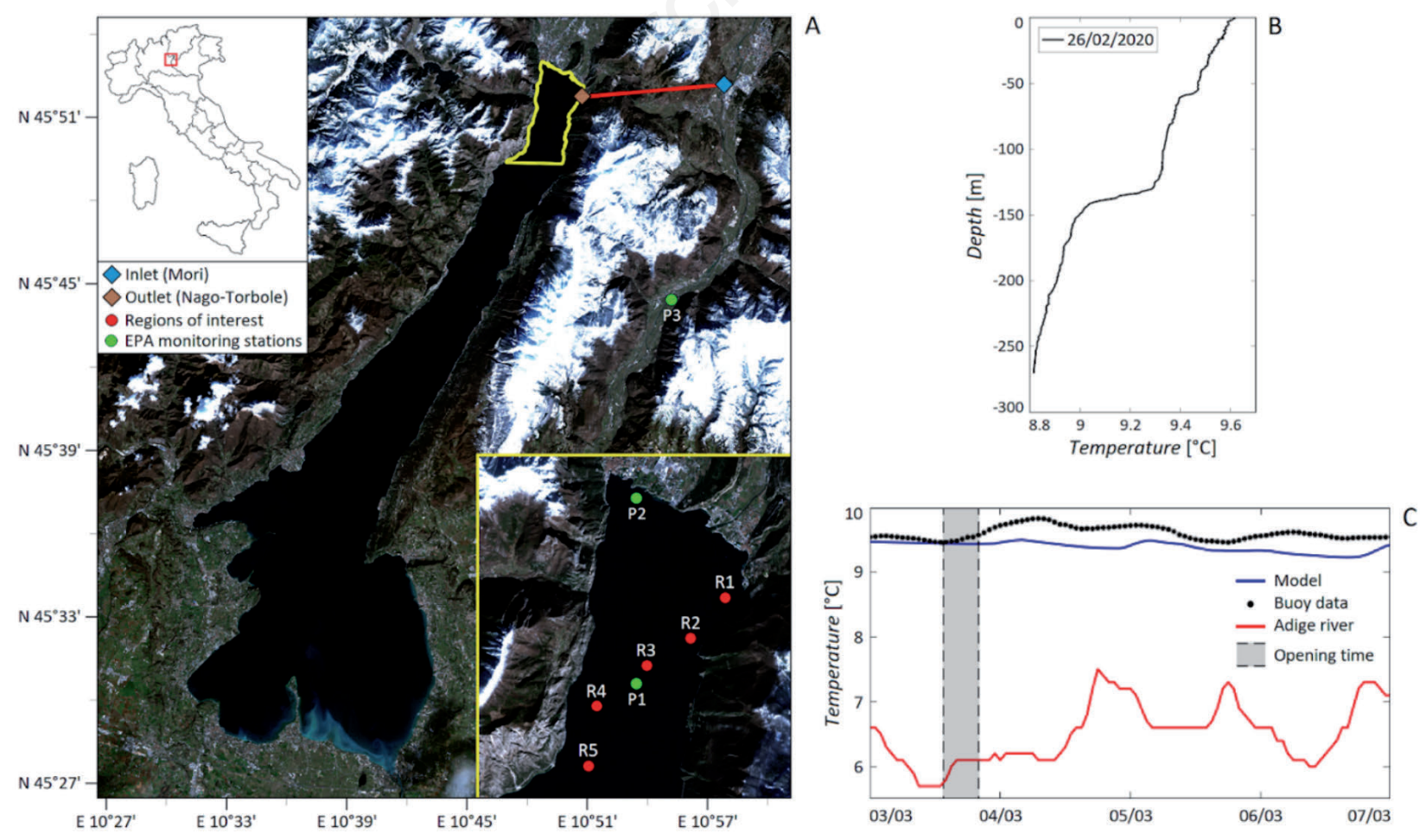

Fig. 1. A) Lake Garda as observed in a Sentinel-2 image (04/03/2020) displayed as true color: the mask used is highlighted in yellow, while the red line represents the Adige-Garda hydraulic tunnel. In the yellow inset (bottom right), red dots (R1-R5) represent the regions of interest used to make comparisons between the available dates, while the green dots represent the monitoring stations: P1 = water temperature profile; P2 = buoy hourly water temperature; P3 = river monitoring station. B) The vertical temperature profile measured at monitoring station (P1) on 26/02/2020. C) Lake water temperature at $10 \mathrm{~m}$ below the surface observed by the buoy (P2, black dots) and modelled (blue line), and river water temperature (P3, red line); the grey shaded area indicates the opening event. 
Tab. 1. Percentage variation of SPM concentration in the five ROIs (R1-R5) from 28/02 to 04/03 and from 04/03 to 07/03, estimated for both satellite and modelled data.

\begin{tabular}{|c|c|c|c|c|}
\hline \multirow[t]{2}{*}{ ROI } & \multicolumn{2}{|c|}{ From $28 / 02$ to $04 / 03(\%)$} & \multicolumn{2}{|c|}{ From 04/03 to 07/03 (\%) } \\
\hline & Satellite & Model & Satellite & Mode \\
\hline R1 & 665 & 891 & -73 & -90 \\
\hline $\mathrm{R} 2$ & 428 & 411 & -72 & -80 \\
\hline R3 & 309 & 306 & -69 & -75 \\
\hline R4 & 252 & 203 & -64 & -64 \\
\hline R5 & 196 & 129 & -58 & -51 \\
\hline
\end{tabular}

A

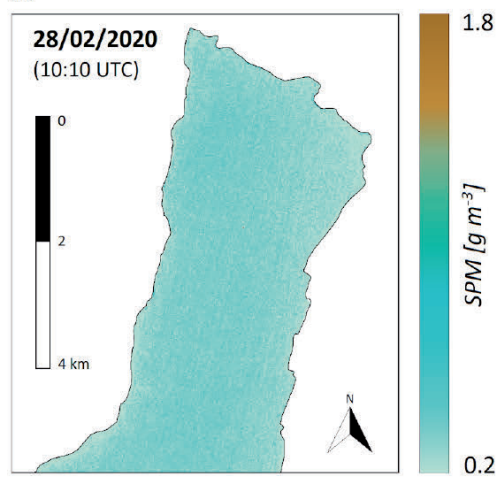

B
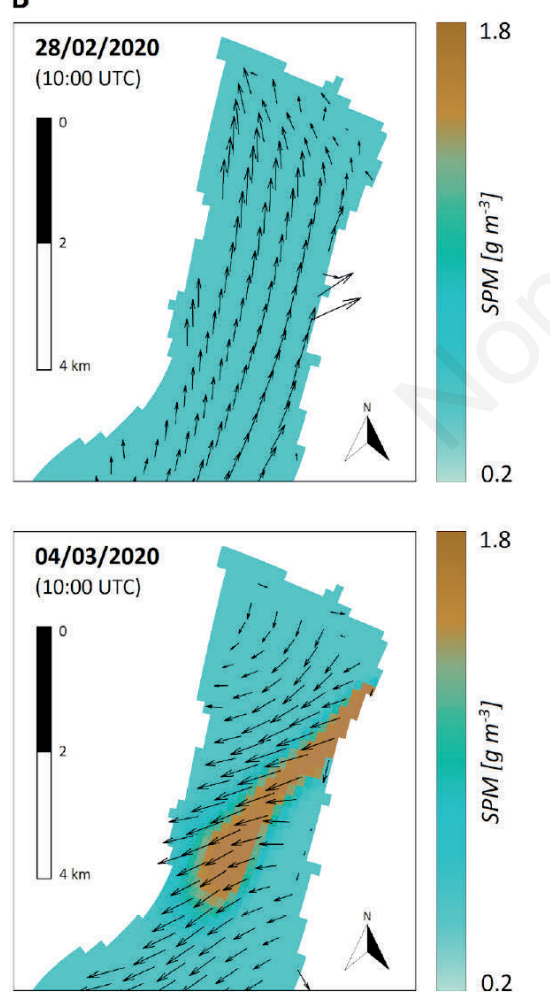
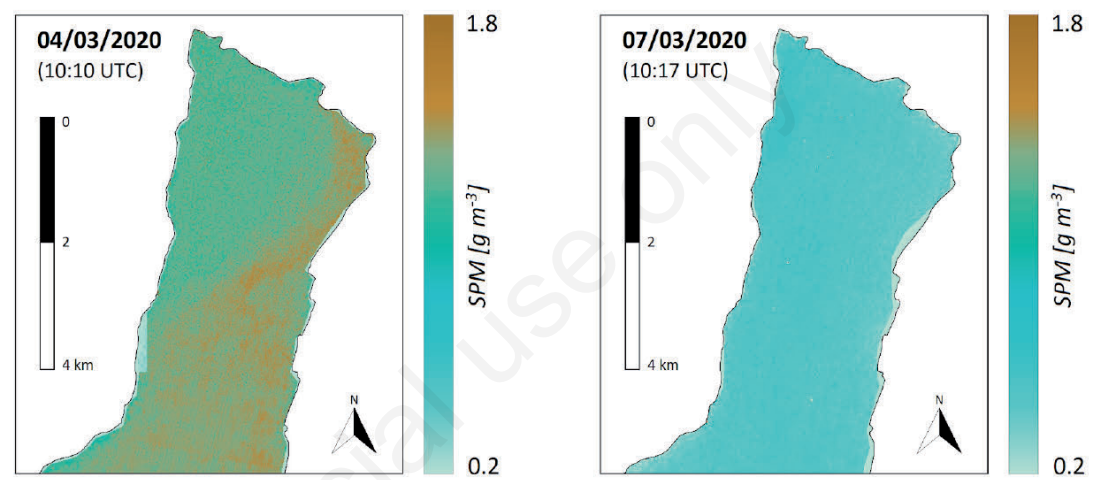

1.8

0.2
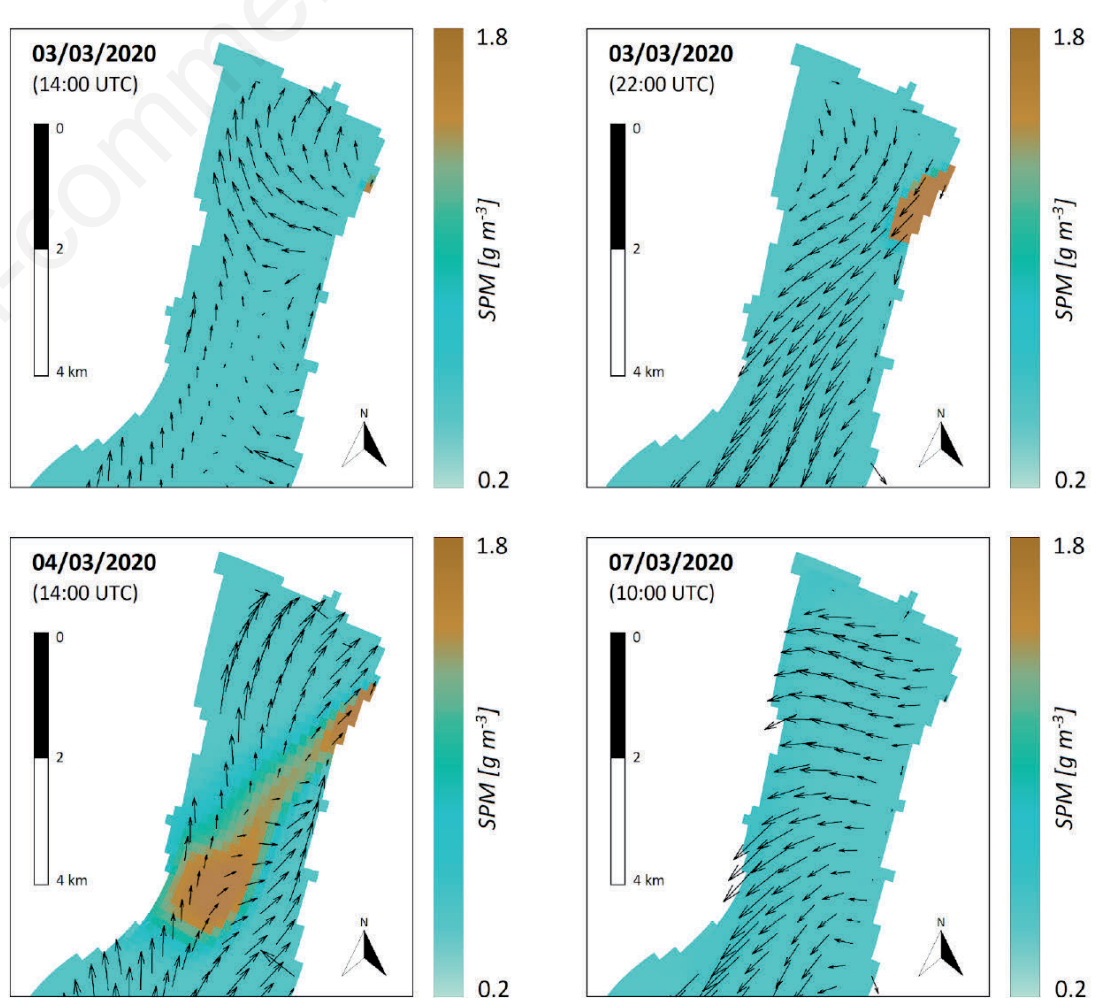

Fig. 2. A) SPM concentration maps obtained through BOMBER for the three available dates (pixel size $=10 \times 10 \mathrm{~m}$ ). B) Numerical tracer concentration and flow field maps at the surface obtained from the hydrodynamic simulations before (28/02), during (03/03) and after the event $(04 / 03,07 / 03)$. Arrows represent the simulated surface velocity vectors. 
numerical model. From the 28/02 to the $04 / 03$ a large increase in SPM concentration was observed for both the satellite and the model estimates, while from the $04 / 03$ to the $07 / 03$ a general decrease of all values was observed.

Fig. 2B shows the model results in terms of flow field and numerical tracer concentration in the surface layer (1 $\mathrm{m}$ thick) from the first date available from S2 maps $(28 / 02)$ until the last date $(07 / 03)$. Between them, four snapshots are provided during the event $(03 / 03$ at $14: 00)$ and after (03/03 at 22:00, 04/03 at 10:00, when the second S2 image was available, and at 14:00). On the 03/03 at 14:00, the discharge of turbid riverine waters can be identified from a localized increase of SPM concentration close to the exit of the Adige Garda tunnel. Since the water discharged by the tunnel is $\sim 3.5^{\circ} \mathrm{C}$ colder than lake epilimnetic temperature (Fig. 1C), the river inflow sinks to deeper layers and no significant changes in surface tracer concentration can be identified during the opening hours. In the subsequent hours (see the snapshot at 22:00 of the same day), the tracer concentration increases along the eastern shore due to the upwelling of the sunken water and the surface cloud moves towards the centre of the lake, following the surface flow field. In the morning of the $04 / 03$, as the surface current keeps pushing water south-west, a horizontal plume develops from the mouth of the tunnel to the opposite south-western shore. In the region where the plume is localized, a significant increase of numerical SPM is found at the time of S2 map of the 04/03 (10:00). The highest values (an increase of up to $891 \%$ ) are located close to the mouth and along the centre of the tracer cloud (Tab. 1). In the afternoon, the surface flow direction reverts and the plume's borders are dissipated, until the full dilution is achieved on the 07/03.

\section{DISCUSSION}

During the period under investigation (from 28/02 to 07/03), the study area underwent substantial variation in SPM concentration, which was clearly visible in the maps produced by BOMBER from the S2 images. In the map immediately after the event (04/03), the shape of the plume detected by means of remote sensing is comparable with the results from the hydrodynamic model. However, the simulated plume is narrower than in the S2 image and the agreement between the numerically modeled and remotely sensed SPM concentration reduces far from the centre of the plume. After the sinking of the river inflow, the resuspension dynamics are due to advection (upwelling) and turbulent diffusion. The deficiency in reproducing the greater dispersion of SPM is likely due to processes that were not included in the model. In particular, SPM was represented as a passive tracer without settling and resuspension; wind waves, which can enhance the surface dispersion, were not parameterized in the model (thus the horizontal diffusion might be underestimated); and, most probable, other sources of SPM were not considered but might have been relevant. Given the limited knowledge on the suspended sediments concentration of the inflowing water and on the granulometric composition of the sediments, the simulation of SPM as a passive tracer represented the only viable option. Hence, we neglected the effect of the suspended sediments on the water density and the difference between lake and river water temperature was considered as the dominant factor driving the initial sinking of the river plume. Moreover, model results were compared with SPM maps one day after the event, when the coarser fractions of the sediments were already settled, and the SPM that appeared at the lake's surface was only the finer fraction that was transported as wash load. Despite the stated limitations, the quantitative agreement between SPM values extracted from S2 and simulated by the model in the ROIs along the plume is very good, both during and after the event. In addition, model outputs complement the $\mathrm{S} 2$ maps in the identification of the SPM plume on the 04/03. By providing additional information on the three-dimensional flow field and thermal structure of the lake, the model reproduces the initial sinking of the plume due to negative buoyancy, the subsequent resuspension of the sediments and confirms the complete dilution of the SPM concentration on the $07 / 03$. Hence, the numerical simulation of the transport in the lake, combined with the SPM concentrations retrieved from $\mathrm{S} 2$, provides a deeper understanding of the physical phenomenon, and may represent an alternative way for evaluating the effects of the opening of the Adige-Garda spillway.

\section{CONCLUSIONS}

The synergic use of the S2 data and of the hydrodynamic model gave us the chance to investigate the effects of the opening of the Adige-Garda spillway on the concentration of SPM in the northernmost part of Lake Garda. The plume detected from S2 is compatible with the flow field and with the surface dispersion of the turbid riverine water obtained with the hydrodynamic model. Both methods allowed the quantification and definition of the spatial and temporal extent of the SPM plume. While remote sensing was suitable for identifying an event and defining its visible extent, the hydrodynamic model allowed understanding how the surface flow field contributed to it, as well as producing estimates of the SPM distribution in the periods between satellite acquisitions.

The results suggest that a simple routine opening of the spillway can cause a significant increase in SPM concentration with respect to the standard conditions in the lake, and its ecological implications on water quality deserve further investigation. In this regard, this work shows 
the potential of the approach combining remote sensing and hydrodynamic modelling for a deeper understanding of the implications of these kind of operations in Lake Garda. Further research effort in this direction is required in order to assess implications and provide useful guidelines to inform management decisions on future openings of the spillway.

\section{ACKNOWLEDGEMENTS}

We thank the environmental agencies of the Autonomous Province of Trento (APPA, Serv. Bacini Montani), Veneto (ARPAV) and Lombardia Regions (ARPAL), and Edmund Mach Foundation (FEM), for kindly providing the data used for the setup of the numerical model (meteorological and water temperature and discharge). Sentinel-2 data were provided by the EU Copernicus program. We thank EOMORES project (H2020, project number 730066). The study is supported by CNR projects DIT.AD012.115.001 (WATER-Sat) and DIT.AD012.024.001. Thanks to the editor and anonymous referees that contributed with constructive comments.

\section{REFERENCES}

Amadori M, Piccolroaz S, Giovannini L, Zardi D, Toffolon M, 2018. Wind variability and Earth's rotation as drivers of transport in a deep, elongated subalpine lake: the case of Lake Garda. J. Limnol. 77:1814.

Amadori M, Morini G, Piccolroaz S, Toffolon M, 2020. Involving citizens in hydrodynamic research: A combined local knowledge - numerical experiment on Lake Garda, Italy. Sci. Total Environ. 722:137720.

Bresciani M, Stroppiana D, Odermatt D, Morabito G, Giardino C, 2011. Assessing remotely sensed chlorophyll-a for the implementation of the Water Framework Directive in European perialpine lakes. Sci. Total Environ. 409:3083-3091.

De Cesare G, Boillat JL, Schleiss AJ, 2006. Circulation in stratified lakes due to flood-induced turbidity currents. J. Environ. Eng. 132:1508-1517.
Giardino C, Candiani G, Bresciani M, Lee Z, Gagliano S, Pepe M, 2012. BOMBER: A tool for estimating water quality and bottom properties from remote sensing images. Comput. Geosci. 45:313-318.

Giardino C, Bresciani M, Cazzaniga I, Schenk K, Rieger P, Braga F, Matta E, Brando VE, 2014. Evaluation of multiresolution satellite sensors for assessing water quality and bottom depth of Lake Garda. Sensors 14:24116-24131.

Jacobsen L, Berg S, Baktoft H, Nilsson PA, Skov C, 2014. The effect of turbidity and prey fish density on consumption rates of piscivorous Eurasian perch Perca fluviatilis. J. Limnol. 73:837.

Kimmel BL, Lind OT, Paulson LJ, 1990. Reservoir primary production, p133-194. In: Thorton KW, Kimmel BL, Payne FE (eds.), Reservoir limnology: Ecological perspectives. J. Wiley \& Sons, Hoboken.

Lesser GR, Roelvink JA, Keste TMV, Stelling GS, 2004. Development and validation of a three-dimensional morphological model. Coast. Eng. 51:883-915.

Premazzi G, Dalmiglio A, Cardoso AC, Chiaudani G, 2003. Lake management in Italy: the implications of the Water Framework Directive. Lakes Reserv. Res. Manag. 8:41-59.

Salmaso N, Mosello R, Garibaldi L, Decet F, Brizzio MC, Cordella P, 2003. Vertical mixing as a determinant of trophic status in deep lakes: a case study from two lakes south of the Alps (Lake Garda and Lake Iseo). J. Limnol. 62(s1):3341. doi: 10.4081/jlimnol.2003.s1.33

Skamarock WC, Klemp JB, Dudhia J, Gill DO, Barker DM, Duda M, Huang XY, Wang W, Powers JGA, 2008. Description of the advanced research WRF version 3. NCAR Technical Note TN-475+STR. 125.

Soulignac F, Danis PA, Bouffard D, Chanudet V, Dambrine E, Guénand Y, Guillermin B, Harmel T, Ibelings B, Kiefer I, Trevisan D, Uittenbogaard R, Anneville O, 2018. Using 3D modelling to understand heterogeneities of surface chlorophyll-a concentration in Lake Geneva. J. Great Lakes Res. 44:756-764.

Syvitski J, Morehead M, Bahr D, Mulder T, 2000. Estimating fluvial sediment transport: the rating parameters. Water Resour. Res. 36:2747-2760.

Vermote EFTD, Tanré D, Deuzé JL, Herman M, Morcrette JJ, Kotchenova SY, 2006. Second simulation of a satellite signal in the solar spectrum-vector (6SV). 6S User Guide Vers. 3:1-55. 